Published in final edited form as:

Cancer Chemother Pharmacol. 2012 April ; 69(4): 1021-1027. doi:10.1007/s00280-011-1798-2.

\title{
Tolerability and pharmacokinetic profile of a sunitinib powder formulation in pediatric patients with refractory solid tumors: a Children's Oncology Group study
}

\author{
Steven G. DuBois,
}

Department of Pediatrics, UCSF School of Medicine, 505 Parnassus Avenue, M646, San

Francisco, CA 94143-0106, USA

\section{Suzanne Shusterman,}

Department of Pediatrics, Dana-Farber Cancer Institute, Children's Hospital Boston, Harvard Medical School, Boston, MA, USA

Joel M. Reid,

Department of Pharmacology, Mayo College of Medicine, Rochester, MN, USA

\section{Ashish M. Ingle,}

Children's Oncology Group Operations Center, Arcadia, CA, USA

Charlotte H. Ahern,

Division of Biostatistics, Dan L. Duncan Cancer Center, Baylor College of Medicine, Houston, TX, USA

\section{Sylvain Baruchel,}

Department of Hematology/Oncology, Hospital for Sick Children, Toronto, ON, Canada

\section{Julia Glade-Bender,}

Department of Pediatrics, Morgan Stanley Children's Hospital, Columbia University School of Medicine, New York, NY, USA

\section{Percy Ivy,}

Cancer Therapy Evaluation Program, National Cancer Institute, Bethesda, MD, USA

\section{Peter C. Adamson, and}

Department of Oncology, Children's Hospital of Philadelphia, University of Pennsylvania, Philadelphia, PA, USA

\section{Susan M. Blaney}

Department of Pediatrics, Texas Children's Cancer Center, Baylor College of Medicine, Houston, TX, USA

Steven G. DuBois: duboiss@peds.ucsf.edu

\section{Abstract}


Purpose-Sunitinib is an oral tyrosine kinase inhibitor of VEGF, PDGF, c-KIT, and flt-3 receptors. A pediatric phase I study of sunitinib capsules identified the maximum tolerated dose as $15 \mathrm{mg} / \mathrm{m}^{2} /$ day. This study was conducted to evaluate sunitinib given as a powder formulation.

Methods-Sunitinib $15 \mathrm{mg} / \mathrm{m}^{2}$ was administered orally daily for 4 weeks on $/ 2$ weeks off to patients $<21$ years old with refractory solid tumors. Sunitinib capsules were opened, and the powder sprinkled onto applesauce or yogurt. Plasma levels of sunitinib and an active metabolite, SU12662, were measured, and pharmacokinetic parameters were estimated.

Results-12 patients, median age 13 (range 4-21) years, were treated. The most common firstcycle toxicities were leucopenia $(n=6)$, fatigue $(n=5)$, neutropenia $(n=4)$, and hypertension $(n=$ 4). Three patients had dose-limiting toxicities (DLTs) in cycle 1 (dizziness/back pain, hand-foot syndrome, and intratumoral hemorrhage/hypoxia). A median peak plasma sunitinib concentration of 21 (range 6-36) $\mathrm{ng} / \mathrm{ml}$ was reached at a median of 4 (range 4-8) $\mathrm{h}$ after the first dose. The median exposure $\left(\mathrm{AUC}_{0-48}\right)$ was 585 (range 196-1,059) $\mathrm{h} \mathrm{ng} / \mathrm{l}$. The median half-life was 23 (range 13-36) h. The median trough concentration measured before day 14 dosing was 32 (range $12-58) \mathrm{ng} / \mathrm{ml}$.

Conclusions-The pharmacokinetic profile of sunitinib appears similar between a powder formulation and published data using capsules. The powder formulation allows patients unable to swallow capsules to receive sunitinib.

\section{Keywords}

Sunitinib; Pediatric; Pharmacokinetics; Formulation

\section{Introduction}

Sunitinib, an oral multi-targeted receptor tyrosine kinase inhibitor of vascular endothelial growth factor receptors (VEGFR), platelet-derived growth factor receptors (PDGFR), cKIT, Flt3, CSF-1 receptor, and RET [1-3], is approved for use in adults with advanced gastrointestinal stromal tumor (GIST) and renal cell carcinoma [4-6]. The approved adult dose is $50 \mathrm{mg} /$ day for 28 days followed by a 14-day break [5, 7]. Following an initial dose of $50 \mathrm{mg}$, adults with cancer typically reach a maximum plasma concentration of 20-30 $\mathrm{ng} / \mathrm{ml}$ within 5-7 h [7, 8]. This dosing leads to an exposure of approximately $350-450 \mathrm{~h} \mathrm{ng} / \mathrm{l}$ and a steady-state trough concentration of 40-80 ng/ml [7, 8]. Apparent clearance in adults has been reported to be $40-501 / \mathrm{h}[7,9]$.

A phase I study of sunitinib capsules in children with refractory solid tumors identified a maximum tolerated dose of $15 \mathrm{mg} / \mathrm{m}^{2} /$ day for 28 days followed by a 14-day break in a cohort of patients without prior anthracycline or cardiac radiation exposure [10]. Adjusting for patient size and dose delivered, the pharmacokinetic profile of sunitinib was similar to the reported adult experience.

The aforementioned studies were conducted with intact sunitinib capsules. Young children and other patient groups have a limited ability to swallow capsules. The current report describes the results of a tolerability and pharmacokinetic study of a powder formulation of sunitinib in children with refractory or recurrent solid tumors. The primary aims of the study 
were to describe the toxicities of sunitinib when administered as a powder sprinkled onto applesauce or yogurt and to characterize the pharmacokinetic profile of this formulation in children. Secondary endpoints included an assessment of antitumor efficacy and pharmacodynamic markers of antiangiogenesis.

\section{Materials and methods}

\section{Patients}

Patients were eligible for participation if they were 2-21 years of age, had histologic diagnosis of solid malignancy with measurable or evaluable disease, and had no known curative options. Patients were required to have a Karnofsky (age >10 years) or Lansky (age $\leq 10$ years) performance score $\geq 50$ and to have recovered from prior therapy. Patients were required to have adequate baseline bone marrow, renal, hepatic, pancreatic, and cardiac function according to defined protocol criteria. Patients with pre-existing hyper- or hypothyroidism were required to have stable thyroid function. Patients could not be receiving concomitant antihypertensive medications and had to have blood pressure $<95$ th percentile for age, height, and gender.

Exclusion criteria included prior anthracycline or cardiac radiation exposure (due to cardiac toxicity observed in the pediatric phase I study); concurrent use of strong CYP3A4 inducers or inhibitors; treatment with agents that might increase the risk of bleeding complications; presence of pleural based tumors; uncontrolled infection; and allergy or intolerance to both applesauce and yogurt. Patients with known central nervous system (CNS) primary tumors or metastatic disease were excluded if they demonstrated any evidence of tumor-associated hemorrhage.

Each treating center's institutional review board approved the protocol. All patients or their legal guardians provided written informed consent before study participation.

\section{Treatment and evaluations}

Patients received sunitinib, $15 \mathrm{mg} / \mathrm{m}^{2} /$ day, orally once daily for 28 days followed by a 14day break, such that the duration of one cycle of therapy was 42 days. Instructions were given to patients and caregivers for administering the drug using the powder within sunitinib capsules sprinkled onto either applesauce or yogurt. Specifically, sunitinib capsules were opened using gentle pressure applied to each end of the capsule while shaking over a level teaspoon of room temperature applesauce or yogurt until no more powder could be seen within the capsules. Patients ate the contents of the spoon without mixing within 30 min of first sprinkling the powder onto the food. These steps were repeated for each capsule required to administer the total daily prescribed dose. Patients were instructed to drink a minimum of $2 \mathrm{oz}$ of water or apple juice after the full dose was administered. Drug was given without regard to other meals. Caregivers limited exposure to the sunitinib powder by using masks and gloves. No pregnant caregivers were to prepare the sunitinib doses.

The total daily sunitinib dose was rounded to the nearest $6.25 \mathrm{mg}$ using a dosing nomogram. Patients were required to receive sunitinib as the powder formulation for the first dose; thereafter, patients who were able to swallow capsules had the option to change back to the 
capsule formulation. Sunitinib was held on the second day of the first cycle so that the terminal half-life could be estimated. Patients without disease progression or unacceptable toxicity could receive up to 18 cycles of therapy.

Patients had routine physical examinations and surveillance laboratory testing to evaluate for toxicity. Electrocardiograms and echocardiograms were obtained during the 4 week of cycles $1,2,3$, and then every third cycle. Thyroid-stimulating hormone (TSH) levels were obtained on day 28 of cycle 1 , days 1 and 28 of cycle 2 , and day 28 of every subsequent odd-numbered cycle.

Toxicities were graded according to the NCI Common Terminology Criteria, version 3.0. Dose-limiting toxicity (DLT) was defined as any of the following that were attributed as at least possibly related to sunitinib: grade 4 neutropenia; grade 4 thrombocytopenia; any grade 4 non-hematologic toxicity; grade 2 cardiac systolic dysfunction; blood pressure $>25 \mathrm{mmHg}$ above the 95th percentile for age, height, and gender; any grade 2 non-hematologic toxicity for $\geq 7$ days that required drug interruption; any non-hematologic toxicity that required drug interruption for $>7$ days; or any grade 3 non-hematologic toxicity with the exception of nausea and vomiting of $<3$ days duration, ALT elevation that returned to baseline prior to the next cycle, AST elevation, fever of $<5$ days duration, electrolyte abnormalities responsive to oral supplementation, and asymptomatic elevations of amylase or lipase resolving to <grade 1 within 7 days of drug interruption.

Patients underwent disease re-evaluation at the end of cycle 1 and then every other cycle. For patients with measurable disease, tumor response was evaluated using RECIST [11].

\section{Pharmacokinetic analysis}

Serial plasma samples were obtained in all patients prior to sunitinib and 1, 2, 4, 6, 8-10, $24-28$, and $48-52 \mathrm{~h}$ after the first dose. In the absence of early withdrawal from study, all patients had trough plasma samples obtained on days 7, 14, 21, and 28 of cycle 1 . Plasma concentrations of sunitinib and its main active metabolite, SU12662, were measured using liquid chromatography-tandem mass spectrometry by Bioanalytical Systems, Inc (BASi; West Lafayette, IN), as previously described [12]. Sunitinib and SU12662 plasma concentration-time data were analyzed by standard non-compartmental methods using WinNonlin Pro (Pharsight Corp; Mountain View, CA).

\section{Biomarker studies}

Blood samples were obtained at baseline and day 28 of cycle 1 in consenting patients to evaluate plasma biomarkers of angiogenesis. VEGF, VEGFR2, placental growth factor (PIGF), and endoglin levels were measured by ELISA using commercially available kits (R\&D Systems, Inc; Minneapolis, MN).

\section{Statistical methods}

Changes in biomarkers of angiogenesis obtained at baseline and at the end of cycle 1 were assessed using the Wilcoxon signed-rank test. 


\section{Results}

\section{Patient characteristics and dose delivery}

Characteristics of the 12 patients treated with sunitinib as a powder formulation are shown in Table 1. Six patients were $<12$ years of age at study entry. Patients received a median of 1 cycle of therapy (range $1-9$ cycles).

Nine patients received sunitinib as a powder formulation throughout the entire first cycle of therapy. Three patients changed to the capsule formulation on days $3(n=2)$ and $8(n=1)$ of the first cycle of therapy. In two of these cases, this change was made due to an aversion to the taste of the powder. For the other patient, this change was made due to the convenience of taking intact capsules. All patients treated with more than one cycle of therapy received sunitinib as intact capsules in subsequent cycles. Due to dose rounding to the nearest 6.25 $\mathrm{mg}$, the 12 patients treated at a planned dose of $15 \mathrm{mg} / \mathrm{m}^{2}$ received a median actual dose of $13.9 \mathrm{mg} / \mathrm{m}^{2}$ (range $12.9-16.6 \mathrm{mg} / \mathrm{m}^{2}$ ).

\section{Toxicity of sunitinib administered as a powder formulation}

Three of 12 patients experienced protocol-defined DLTs during the first cycle of therapy. These included grade 3 dizziness with back pain; grade 3 hand-foot syndrome; and grade 4 hypoxia in the setting of bleeding into a known site of a primary CNS tumor. The latter two patients had changed from powder formulation to intact capsule formulation on days 8 and 3 of cycle 1, respectively. DLTs occurred on days 22 and 17 of cycle 1, respectively. Two patients developed protocol-defined DLTs in subsequent cycles of therapy while receiving sunitinib as intact capsules: grade 3 proteinuria and grade 3 alkaline phosphatase.

Additional non-dose-limiting toxicities observed in more than $10 \%$ of patients in the first cycle of therapy are shown in Table 2 . The most common first-cycle toxicities were leucopenia $(n=6)$, fatigue $(n=5)$, neutropenia $(n=4)$, and hypertension $(n=4)$. Two patients developed grade 1 increased thyroid-stimulating hormone levels during the first course of therapy.

\section{Pharmacokinetics}

Pharmacokinetic parameters for the 12 patients treated with the powder formulation are shown in Table 3. For comparative purposes, previously published parameters are also presented for pediatric patients treated with a dose of $15 \mathrm{mg} / \mathrm{m}^{2}$ using the capsule formulation [10].

All 12 patients provided serial plasma samples following the first dose of the powder formulation for the determination of pharmacokinetic parameters (Table 3). The time to maximal sunitinib concentration $\left(T_{\max }\right)$ appeared to be earlier with the powder formulation compared to the capsule formulation (median $4.0 \mathrm{~h}$ vs. $7.0 \mathrm{~h}$, respectively). Despite this difference, the peak plasma sunitinib concentration did not appear to differ between the two formulations (median $21.3 \mathrm{ng} / \mathrm{ml}$ vs. $16.8 \mathrm{ng} / \mathrm{ml}$, respectively). Other pharmacokinetic parameters for sunitinib or its metabolite, SU12662, did not appear to differ substantially between powder and capsule formulations. 
Ten patients submitted at least one sample for the evaluation of steady-state trough levels while still receiving sunitinib as the powder formulation (Fig. 1). Median trough concentrations of sunitinib, the active metabolite SU12662, and total drug (sunitinib + SU12662) were similar on days $7,14,21$, and 28 , with steady state reached by day 7 . At each time point, no more than one-third of patients receiving powder formulation had total drug trough concentrations $>50 \mathrm{ng} / \mathrm{ml}$, the target concentration derived from preclinical studies [2]. Two of the three patients with DLT in the first course had day 7 total drug trough concentrations $>50 \mathrm{ng} / \mathrm{ml}$.

\section{Antitumor activity}

Six of 12 patients had disease progression in the first cycle of therapy. Two patients with high-grade glioma and ependymoma had confirmed stable disease for 3 and 9 cycles, respectively. Both patients received the capsule formulation after the first cycle of therapy and remain on study therapy.

\section{Plasma biomarkers of angiogenesis}

Five patients had paired baseline and day 28 plasma samples available for the evaluation of angiogenic factor biomarkers by ELISA. Plasma-soluble VEGFR2 levels decreased significantly over 28 days of therapy [median baseline level 10,072 ng/ml (range, 7,840$11,243$ ) versus 6,821 (range $6,304-10,169) \mathrm{ng} / \mathrm{ml}$ at day $28 ; P=0.043]$. Similarly, plasma endoglin levels decreased over the first cycle of therapy [median baseline level 4.4 (range $3.8-5.8) \mathrm{pg} / \mathrm{ml}$ versus 3.8 (range 3.0-4.6) $\mathrm{pg} / \mathrm{ml}$ at day $28 ; P=0.043$ ]. Plasma VEGF and placental growth factor levels did not change consistently with sunitinib therapy.

\section{Discussion}

Sunitinib is commercially available as capsules, limiting availability of this oral antiangiogenic agent to patients who are able to swallow intact capsules. The current study provides detailed clinical, pharmacokinetic, and pharmacodynamic data for the administration of sunitinib using the active drug contained within sunitinib capsules. The results of this study indicate that sunitinib administration as powder on applesauce or yogurt provides an alternative mode of administration for patients who are unable to swallow capsules. While this study was conducted in children, the results may apply to adults since the pharmacokinetics of sunitinib appear similar in these two populations, accounting for differences in dose received and patient size. Therefore, young children and older patients with swallowing dysfunction may benefit from the current findings.

Prior to the current study, two previous reports described alternative sunitinib formulations $[13,14]$. In one study, a powder in bottle formulation was developed specifically for first in human clinical testing [14]. This formulation is not commercially available. In the second study, a sunitinib suspension was developed using commercially available capsules, though clinical results with this extemporaneous formulation are not available [13].

The toxicity profile of sunitinib in the current study was similar to previous evaluation of sunitinib in children $[10,15]$. Although $3 / 12$ patients in the current study had protocoldefined DLTs in the first cycle and 0/6 patients had DLTs with this same dose in the 
previous phase I study of sunitinib capsules, this finding most likely reflects the small number of patients receiving these formulations since the pharmacokinetic profile of the two modes of administration was similar. Moreover, two of the patients with DLT in the current study changed from the powder to capsule formulation 14 days prior to onset of DLT.

The pharmacokinetic parameters estimated following day 1 dosing were approximately similar between children receiving either powder or capsule formulation [10] although an earlier time to maximal concentration was observed with the powder formulation. At steady state, median sunitinib, SU12662, and total drug concentrations were similar between powder and capsule formulations. However, a lower proportion of patients treated with the powder formulation had total drug concentrations that exceeded the target concentration of $50 \mathrm{ng} / \mathrm{ml}$ compared with results observed with the capsule formulation [10]. Specifically, weekly trough total drug concentrations were $>50 \mathrm{ng} / \mathrm{ml}$ in at least a third of patients treated with capsules, while less than a third of patients achieved these levels with the powder formulation in the current study. Plasma concentrations were obtained using identical blood sampling and plasma analysis methods in both studies, decreasing the likelihood that any observed differences may reflect methodological differences. Additional studies with larger numbers of patients will be necessary to determine whether the steady-state pharmacologic properties of these two formulations differ.

In previous studies, a decrease in soluble VEGFR2 has been among the most consistent pharmacodynamic markers of sunitinib activity [16-18]. This same finding was previously observed in pediatric patients treated with sunitinib capsules, along with decreases in plasma endoglin [10]. In the current study, these same biomarkers were modulated using sunitinib given as a powder formulation, indicating pharmacodynamic activity with this dose and formulation.

In conclusion, the pharmacokinetic profile of a sunitinib powder formulation appears similar to results obtained with capsules, though trough levels may be lower with the powder formulation. A similar range of toxicities was observed with the powder formulation compared to previous studies of capsules. Pharmacodynamic modulation of angiogenesisrelated biomarkers was also achieved with the powder formulation at the maximum tolerated pediatric dose of $15 \mathrm{mg} / \mathrm{m}^{2}$. Given these findings, administration of sunitinib as a powder formulation to patients unable to swallow capsules appears to be feasible.

\section{Acknowledgments}

This study was supported by the Campini Foundation, Pfizer, NIH/NCRR/OD UCSF-CTSI Grant Number KL2 RR024130, and NCI U01 CA97452. Pfizer provided partial support for the analyses of sunitinib pharmacokinetics.

\section{References}

1. Abrams TJ, Lee LB, Murray LJ, Pryer NK, Cherrington JM. SU11248 inhibits KIT and plateletderived growth factor receptor beta in preclinical models of human small cell lung cancer. Mol Cancer Ther. 2003; 2:471-478. [PubMed: 12748309]

2. Mendel DB, Laird AD, Xin X, Louie SG, Christensen JG, Li G, Schreck RE, Abrams TJ, Ngai TJ, Lee LB, Murray LJ, Carver J, Chan E, Moss KG, Haznedar JO, Sukbuntherng J, Blake RA, Sun L, Tang C, Miller T, Shirazian S, McMahon G, Cherrington JM. In vivo antitumor activity of 
SU11248, a novel tyrosine kinase inhibitor targeting vascular endothelial growth factor and plateletderived growth factor receptors: determination of a pharmacokinetic/pharmacodynamic relationship. Clin Cancer Res. 2003; 9:327-337. [PubMed: 12538485]

3. O'Farrell AM, Abrams TJ, Yuen HA, Ngai TJ, Louie SG, Yee KW, Wong LM, Hong W, Lee LB, Town A, Smolich BD, Manning WC, Murray LJ, Heinrich MC, Cherrington JM. SU11248 is a novel FLT3 tyrosine kinase inhibitor with potent activity in vitro and in vivo. Blood. 2003; 101:3597-3605. [PubMed: 12531805]

4. Demetri GD, van Oosterom AT, Garrett CR, Blackstein ME, Shah MH, Verweij J, McArthur G, Judson IR, Heinrich MC, Morgan JA, Desai J, Fletcher CD, George S, Bello CL, Huang X, Baum CM, Casali PG. Efficacy and safety of sunitinib in patients with advanced gastrointestinal stromal tumour after failure of imatinib: a randomised controlled trial. Lancet. 2006; 368:1329-1338. [PubMed: 17046465]

5. Goodman VL, Rock EP, Dagher R, Ramchandani RP, Abraham S, Gobburu JV, Booth BP, Verbois SL, Morse DE, Liang CY, Chidambaram N, Jiang JX, Tang S, Mahjoob K, Justice R, Pazdur R. Approval summary: sunitinib for the treatment of imatinib refractory or intolerant gastrointestinal stromal tumors and advanced renal cell carcinoma. Clin Cancer Res. 2007; 13:1367-1373. [PubMed: 17332278]

6. Motzer RJ, Hutson TE, Tomczak P, Michaelson MD, Bukowski RM, Rixe O, Oudard S, Negrier S, Szczylik C, Kim ST, Chen I, Bycott PW, Baum CM, Figlin RA. Sunitinib versus interferon alfa in metastatic renal-cell carcinoma. N Engl J Med. 2007; 356:115-124. [PubMed: 17215529]

7. Faivre S, Delbaldo C, Vera K, Robert C, Lozahic S, Lassau N, Bello C, Deprimo S, Brega N, Massimini G, Armand JP, Scigalla P, Raymond E. Safety, pharmacokinetic, and antitumor activity of SU11248, a novel oral multitarget tyrosine kinase inhibitor, in patients with cancer. J Clin Oncol. 2006; 24:25-35. [PubMed: 16314617]

8. Britten CD, Kabbinavar F, Hecht JR, Bello CL, Li J, Baum C, Slamon D. A phase I and pharmacokinetic study of sunitinib administered daily for 2 weeks, followed by a 1-week off period. Cancer Chemother Pharmacol. 2008; 61:515-524. [PubMed: 17505827]

9. Houk BE, Bello CL, Kang D, Amantea M. A population pharmacokinetic meta-analysis of sunitinib malate (SU11248) and its primary metabolite (SU12662) in healthy volunteers and oncology patients. Clin Cancer Res. 2009; 15:2497-2506. [PubMed: 19258444]

10. DuBois SG, Shusterman S, Ingle AM, Ahern CH, Reid JM, Wu B, Baruchel S, Glade-Bender J, Ivy SP, Grier HE, Adamson PC, Blaney SM. Phase I and Pharmacokinetic Study of Sunitinib in Pediatric Patients with Refractory Solid Tumors: A Children's Oncology Group Study. Clin Cancer Res. 2011; 17:5113-5122. [PubMed: 21690570]

11. Therasse P, Arbuck SG, Eisenhauer EA, Wanders J, Kaplan RS, Rubinstein L, Verweij J, Van Glabbeke M, van Oosterom AT, Christian MC, Gwyther SG. New guidelines to evaluate the response to treatment in solid tumors. European Organization for Research and Treatment of Cancer, National Cancer Institute of the United States, National Cancer Institute of Canada. J Natl Cancer Inst. 2000; 92:205-216. [PubMed: 10655437]

12. Bello CL, Sherman L, Zhou J, Verkh L, Smeraglia J, Mount J, Klamerus KJ. Effect of food on the pharmacokinetics of sunitinib malate (SU11248), a multi-targeted receptor tyrosine kinase inhibitor: results from a phase I study in healthy subjects. Anticancer Drugs. 2006; 17:353-358. [PubMed: 16520665]

13. Navid F, Christensen R, Minkin P, Stewart CF, Furman WL, Baker S. Stability of sunitinib in oral suspension. Ann Pharmacother. 2008; 42:962-966. [PubMed: 18577759]

14. Sistla A, Sunga A, Phung K, Koparkar A, Shenoy N. Powder-in-bottle formulation of SU011248. Enabling rapid progression into human clinical trials. Drug Dev Ind Pharm. 2004; 30:19-25. [PubMed: 15000426]

15. Janeway KA, Albritton KH, Van Den Abbeele AD, D'Amato GZ, Pedrazzoli P, Siena S, Picus J, Butrynski JE, Schlemmer M, Heinrich MC, Demetri GD. Sunitinib treatment in pediatric patients with advanced GIST following failure of imatinib. Pediatr Blood Cancer. 2009; 52:767-771. [PubMed: 19326424]

16. Norden-Zfoni A, Desai J, Manola J, Beaudry P, Force J, Maki R, Folkman J, Bello C, Baum C, DePrimo SE, Shalinsky DR, Demetri GD, Heymach JV. Blood-based biomarkers of SU11248 
activity and clinical outcome in patients with metastatic imatinib-resistant gastrointestinal stromal tumor. Clin Cancer Res. 2007; 13:2643-2650. [PubMed: 17473195]

17. Rini BI, Michaelson MD, Rosenberg JE, Bukowski RM, Sosman JA, Stadler WM, Hutson TE, Margolin K, Harmon CS, DePrimo SE, Kim ST, Chen I, George DJ. Antitumor activity and biomarker analysis of sunitinib in patients with bevacizumab-refractory metastatic renal cell carcinoma. J Clin Oncol. 2008; 26:3743-3748. [PubMed: 18669461]

18. Zhu AX, Sahani DV, Duda DG, di Tomaso E, Ancukiewicz M, Catalano OA, Sindhwani V, Blaszkowsky LS, Yoon SS, Lahdenranta J, Bhargava P, Meyerhardt J, Clark JW, Kwak EL, Hezel AF, Miksad R, Abrams TA, Enzinger PC, Fuchs CS, Ryan DP, Jain RK. Efficacy, safety, and potential biomarkers of sunitinib monotherapy in advanced hepatocellular carcinoma: a phase II study. J Clin Oncol. 2009; 27:3027-3035. [PubMed: 19470923] 

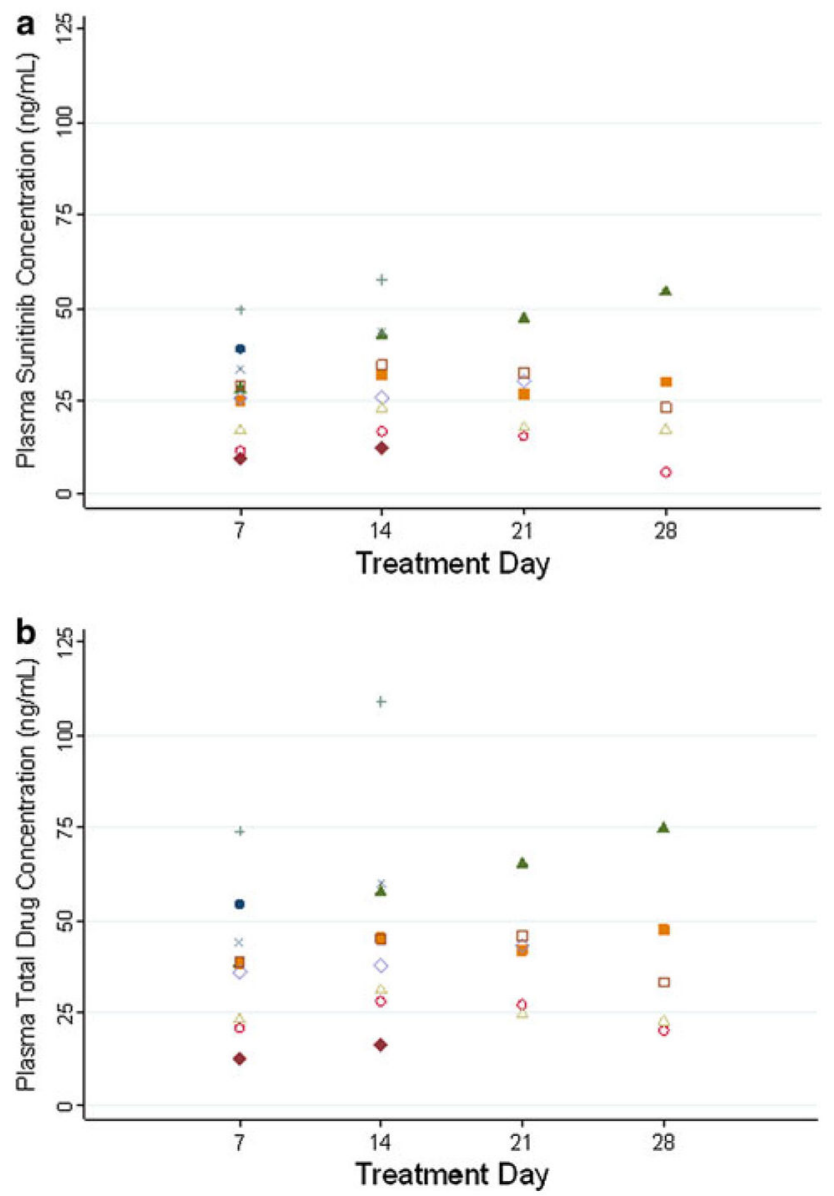

Fig. 1.

Trough plasma concentrations (ng/ml) of sunitinib (a) and total drug (sunitinib plus SU12662) (b) on days 7-28 of sunitinib therapy $\left(15 \mathrm{mg} / \mathrm{m}^{2}\right)$ in 10 patients treated with powder formulation. Values reflect only patients who were receiving the powder formulation on the given days 


\section{Table 1}

Characteristics of 12 patients treated with powder formulation of sunitinib

\begin{tabular}{ll}
\hline & $N=\mathbf{1 2}$ \\
\hline Median age, years (range) & $13.1(4.2-21.5)$ \\
Boys : Girls & $5: 7$ \\
Diagnosis & \\
$\quad$ High-grade glioma & 5 \\
Brain stem glioma & 4 \\
Ependymoma & 1 \\
Mesothelioma & 1 \\
$\quad$ Undifferentiated carcinoma & 1 \\
Prior receptor tyrosine kinase inhibitor & $2^{a}$ \\
Median number sunitinib cycles (range) & $1(1-9)$ \\
\hline
\end{tabular}

${ }^{a}$ Pazopanib $(n=1)$ and erlotinib $(n=1)$ 


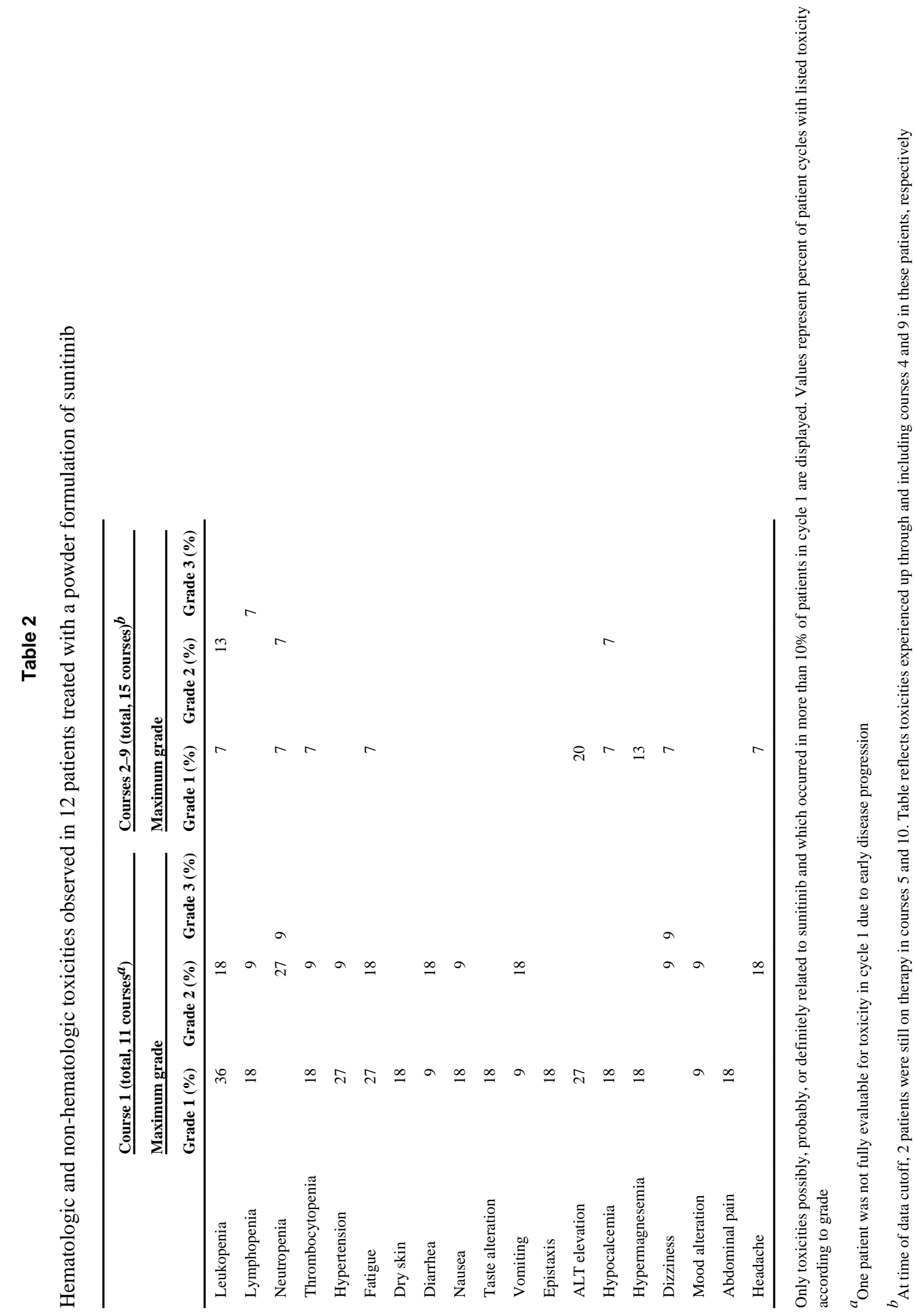

Cancer Chemother Pharmacol. Author manuscript; available in PMC 2014 May 02. 


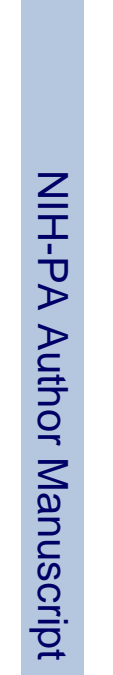

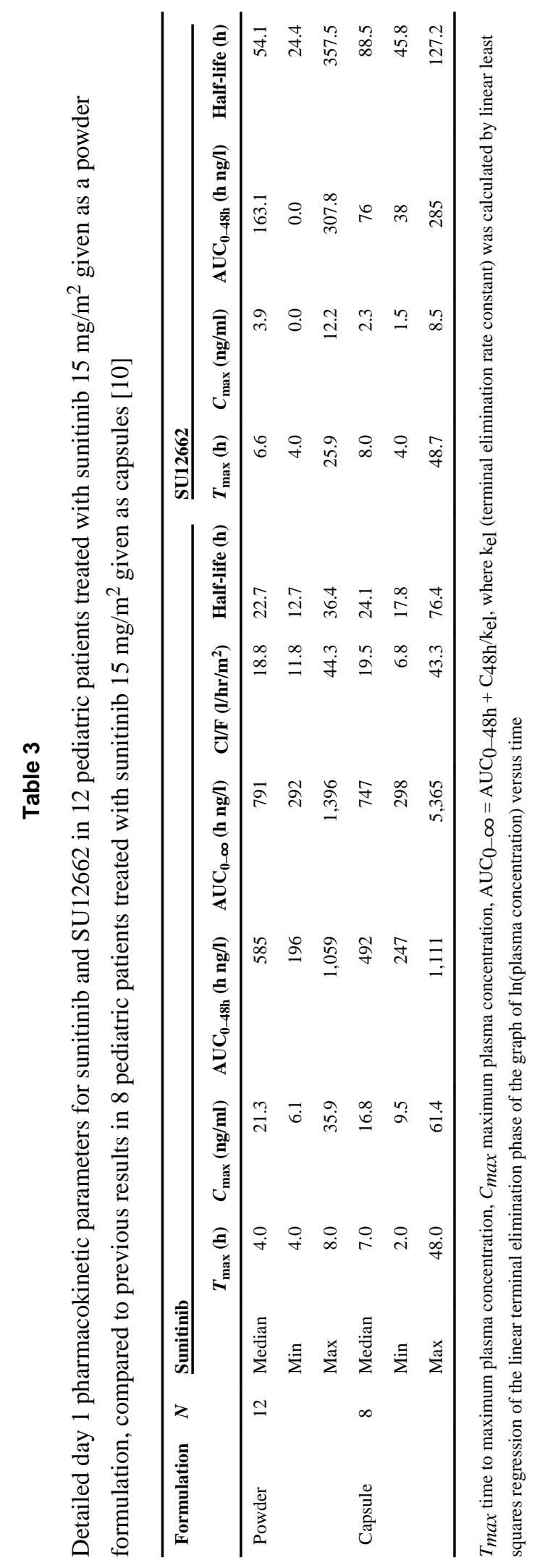

